\title{
Variational Iteration Method for Fifth-Order Boundary Value Problems Using He's Polynomials
}

\author{
Muhammad Aslam Noor and Syed Tauseef Mohyud-Din \\ Department of Mathematics, COMSATS Institute of Information Technology, Islamabad 44000, Pakistan
}

Correspondence should be addressed to Muhammad Aslam Noor, noormaslam@hotmail.com

Received 8 January 2008; Revised 31 January 2008; Accepted 5 March 2008

Recommended by David Chelidze

\begin{abstract}
We apply the variational iteration method using He's polynomials (VIMHP) for solving the fifthorder boundary value problems. The proposed method is an elegant combination of variational iteration and the homotopy perturbation methods and is mainly due to Ghorbani (2007). The suggested algorithm is quite efficient and is practically well suited for use in these problems. The proposed iterative scheme finds the solution without any discritization, linearization, or restrictive assumptions. Several examples are given to verify the reliability and efficiency of the method. The fact that the proposed technique solves nonlinear problems without using Adomian's polynomials can be considered as a clear advantage of this algorithm over the decomposition method.
\end{abstract}

Copyright ( 2008 M. A. Noor and S. T. Mohyud-Din. This is an open access article distributed under the Creative Commons Attribution License, which permits unrestricted use, distribution, and reproduction in any medium, provided the original work is properly cited.

\section{Introduction}

In this paper, we general fifth-order boundary value problem

$$
y^{(v)}(x)=g(x) y+q(x)
$$

with boundary conditions

$$
y(a)=A_{1}, \quad y^{\prime}(a)=A_{2}, \quad y^{\prime \prime}(a)=A_{3}, \quad y(b)=B_{1}, \quad y^{\prime}(b)=B_{2},
$$

where $y(x)$ and $f(x, y)$ are real and as many times differentiable as required for $x \in[a, b]$; and $A_{i}, i=1,2,3$ and $B_{i}, i=1,2$ are real finite constants. This type of boundary value problems arises in the mathematical modeling of the viscoelastic flows and other branches of mathematical, physical, and engineering sciences, see [1-7] and the references therein. Several numerical 
methods including spectral Galerkin and collocation, decomposition, and sixth-order B-spline have been developed for solving fifth-order boundary value problems, see $[1,7]$ and the references therein. The use of spline function in the context of fifth-order boundary value problems was studied by Fyfe [3], who used the quintic polynomial spline functions to develop consistency relation connecting the values of solution with fifth-order derivative at the respective nodal points. He [8-18] developed the variational iteration method and homotopy perturbation method for solving linear, nonlinear, initial, and boundary value problems. It is worth mentioning that the origin of variational iteration method can be traced back to Inokuti et al. [19], but the real potential of this technique was explored by He [13-18]. Moreover, He realized the physical significance of the variational iteration method, its compatibility with the physical problems and applied this promising technique to a wide class of linear and nonlinear, ordinary, partial, deterministic, or stochastic differential equation; see [13-18]. The homotopy perturbation method $[8-12,17]$ was also developed by He by merging two techniques: the standard homotopy and the perturbation. The homotopy perturbation method was formulated by taking the full advantage of the standard homotopy and perturbation methods. The variational iteration method and homotopy perturbation method have been applied to a wide class of functional equations; see $[4,5,8-36]$ and the references therein. In these methods, the solution is given in an infinite series usually converging to an accurate solution, see $[4,5,8-22,25-36]$ and the references therein. In a later work, Ghorbani $[23,24]$ splits the nonlinear term into a series of polynomials calling them as He's polynomials. Recently, Noor and Mohyud-Din used homotopy perturbation, variational iteration, and the iterative methods [46] for solving the fifth-order boundary value problems. The results are very encouraging and reveal the complete reliability of the new algorithm.

Inspired and motivated by the ongoing research in this area, we use the variational iteration method coupled with He's polynomials for solving the fifth-order boundary value problems in this paper. It is worth mentioning that the proposed method is an elegant combination of variational iteration and the homotopy perturbation methods and is mainly due to Ghorbani $[23,24]$. The use of He's polynomials in the nonlinear term was first introduced by Ghorbani, see $[23,24]$. The proposed algorithm provides the solution in a rapid convergent series which may lead the solution in a closed form. In this technique, the correction functional is developed [13-22] and the Lagrange multipliers are calculated optimally via variational theory. The use of Lagrange multipliers reduces the successive application of the integral operator and the cumbersome of huge computational work, while still maintaining a very high level of accuracy. Finally, He's polynomials are introduced in the correction functional and the comparison of like powers of $p$ gives solutions of various orders. The proposed iterative scheme takes full advantage of variational iteration method and the homotopy perturbation method. It is worth mentioning that the suggested method is applied without any discritization, restrictive assumption, or transformation and is free from round off errors. Unlike the method of separation of variables that requires initial and boundary conditions, the method provides an analytical solution by using the initial conditions only. The proposed method works efficiently and the results so far are very encouraging and reliable. The fact that the proposed VIMHP solves nonlinear problems without using Adomian's polynomials can be considered as a clear advantage of this method over the decomposition method. Several examples are given to verify the reliability and efficiency of the algorithm. 


\section{Variational iteration method}

To illustrate the basic concept of the technique, we consider the following general differential equation:

$$
L u+N u=g(x)
$$

where $L$ is a linear operator, $N$ a nonlinear operator, and $g(x)$ is the forcing term. According to variational iteration method $[5,13-22,25,32-36]$, we can construct a correct functional as follows:

$$
u_{n+1}(x)=u_{n}(x)+\int_{0}^{x} \lambda\left(L u_{n}(s)+N \tilde{u}_{n}(s)-g(s)\right) d s,
$$

where $\lambda$ is a Lagrange multiplier [13-19], which can be identified optimally via variational iteration method. The subscripts $n$ denote the $n$th approximation, $\tilde{u}_{n}$ is considered as a restricted variation, that is, $\delta \tilde{u}_{n}=0$; and (2.2) is called as a correct functional. The solution of the linear problems can be solved in a single iteration step due to the exact identification of the Lagrange multiplier. The principles of variational iteration method and its applicability for various kinds of differential equations are given in [13-19]. In this method, it is required first to determine the Lagrange multiplier $\lambda$ optimally. The successive approximation $u_{n+1}, n \geq 0$ of the solution $u$ will be readily obtained upon using the determined Lagrange multiplier and any selective function $u_{0}$, consequently, the solution is given by

$$
u=\lim _{n \rightarrow \infty} u_{n}
$$

For the convergence and error estimates of variational iteration method, see Ramos [35].

\section{Homotopy perturbation method}

To explain the homotopy perturbation method, we consider a general equation of the type

$$
L(u)=0,
$$

where $L$ is an integral or differential operator. We define a convex homotopy $H(u, p)$ by

$$
H(u, p)=(1-p) F(u)+p L(u),
$$

where $F(u)$ is a functional operator with known solutions $v_{0}$, which can be obtained easily. It is clear that for

$$
H(u, p)=0,
$$

we have

$$
H(u, 0)=F(u), \quad H(u, 1)=L(u) .
$$


This shows that $H(u, p)$ continuously traces an implicitly defined curve from a starting point $H\left(v_{0}, 0\right)$ to a solution function $H(f, 1)$. The embedding parameter monotonically increases from zero to unit as the trivial problem $F(u)=0$ is continuously deforms the original problem $L(u)=0$. The embedding parameter $p \in(0,1]$ can be considered as an expanding parameter $[3,8-11,23,24]$. The homotopy perturbation method uses the homotopy parameter $p$ as an expanding parameter $[4,8-12,23,24,27-31]$ to obtain

$$
u=\sum_{i=0}^{\infty} p^{i} u_{i}=u_{0}+p u_{1}+p^{2} u_{2}+p^{3} u_{3}+\cdots
$$

If $p \rightarrow 1$, then (3.5) corresponds to (3.2) and becomes the approximate solution of the form

$$
f=\lim _{p \rightarrow 1} u=\sum_{i=0}^{\infty} u_{i}
$$

It is well known that series (3.6) is convergent for most of the cases and also the rate of convergence depends upon $L(u)$; see [4, 8-12, 23, 24, 27-31]. We assume that (3.6) has a unique solution. The comparisons of like powers of $p$ give solutions of various orders.

\section{Variational iteration method using He's polynomials (VIMHP)}

To illustrate the basic concept of the variational homotopy perturbation method, we consider the following general differential equation:

$$
L u+N u=g(x)
$$

where $L$ is a linear operator, $N$ a nonlinear operator, and $g(x)$ is the forcing term. According to variational iteration method [5, 6, 13-22, 25, 26, 32-36], we can construct a correct functional as follows:

$$
u_{n+1}(x)=u_{n}(x)+\int_{0}^{x} \lambda(\xi)\left(L u_{n}(\xi)+N \tilde{u}_{n}(\xi)-g(\xi)\right) d \xi
$$

where $\lambda$ is a Lagrange multiplier [13-19], which can be identified optimally via variational iteration method. The subscripts $n$ denote the $n$th approximation, $\tilde{u}_{n}$ is considered as a restricted variation, that is, $\delta \tilde{u}_{n}=0$; and (4.2) is called as a correct functional. Now, we apply the homotopy perturbation method

$$
\sum_{n=0}^{\infty} p^{(n)} u_{n}=u_{0}(x)+p \int_{0}^{x} \lambda(\xi)\left(\sum_{n=0}^{\infty} p^{(n)} L\left(u_{n}\right)+\sum_{n=0}^{\infty} p^{(n)} N\left(\tilde{u}_{n}\right)\right) d \xi-\int_{0}^{x} \lambda(\xi) g(\xi) d \xi
$$

which is the coupling of variational iteration and He's polynomials. The comparison of like powers of $p$ gives solutions of various orders. 


\section{Numerical applications}

In this section, we apply the variational iteration method using He's polynomials (VIMHP) for solving the fifth-order boundary value problems. We develop the correct functional and calculate the Lagrange multipliers optimally via variational theory, which reduces the successive application of the integral operator. The selection of initial value is done carefully because the approximants are heavily dependant upon initial value. He's polynomials are introduced in the correct functional and finally, the comparison of like powers of $p$ gives solutions of various orders. Numerical results are very encouraging. For the sake of comparison, we take the same examples as used in [4-7].

Example 5.1 (see [4-7]). Consider the following nonlinear boundary value problem of fifthorder,

$$
y^{(v)}(x)=e^{-x} y^{2}(x)
$$

with boundary conditions

$$
y(0)=y^{\prime}(0)=y^{\prime \prime}(0)=1 ; \quad y(1)=y^{\prime}(1)=e .
$$

The exact solution for this problem is

$$
y(x)=e^{x} .
$$

The correct functional for the boundary value problem (5.1) and (5.2) is given as

$$
y_{n+1}(x)=y_{n}(x)+\int_{0}^{x} \lambda(s)\left(\frac{d^{5} y_{n}}{d x^{5}}-e^{-x} \tilde{y}_{n}^{2}(x)\right) d s .
$$

Making the correct functional stationary, using $\lambda=(1 / 4 !)(s-x)^{4}$, as the Lagrange multiplier $[13-18,36]$, we get the following iterative formula:

$$
\begin{aligned}
& y_{n+1}(x)=y_{n}(x)+\int_{0}^{x} \frac{1}{4 !}(s-x)^{4}\left(\frac{d^{5} y_{n}}{d x^{5}}-e^{-x} \tilde{y}_{n}^{2}(x)\right) d s, \\
& y_{n+1}(x)=1+x+\frac{1}{2 !} x^{2}+\frac{1}{3 !} A x^{3}+\frac{1}{4 !} B x^{4}+\int_{0}^{x} \frac{1}{4 !}(s-x)^{4}\left(\frac{d^{5} y_{n}}{d x^{5}}-e^{-x} \tilde{y}_{n}^{2}(x)\right) d s,
\end{aligned}
$$

where

$$
A=y^{\prime \prime \prime}(0), \quad B=y^{(i v)}(0) .
$$

Applying the variational iteration method using He's polynomials,

$$
\begin{aligned}
y_{0}+p y_{1}+p^{2} y_{2}+\cdots= & +x+\frac{1}{2 !} x^{2}+\frac{1}{3 !} A x^{3}+\frac{1}{4 !} B x^{4} \\
& +p \int_{0}^{x} \frac{1}{4 !}(s-x)^{4}\left(\frac{d^{5} y_{0}}{d x^{5}}+p \frac{d^{5} y_{1}}{d x^{5}}+p^{2} \frac{d^{5} y_{2}}{d x^{5}}+p^{3} \frac{d^{5} y_{3}}{d x^{5}}+\cdots\right) d s \\
& -p \int_{0}^{x} \frac{1}{4 !}(s-x)^{4} e^{-x}\left(\tilde{y}_{0}+p \tilde{y}_{1}+p^{2} \tilde{y}_{2}+\cdots\right)^{2} d s
\end{aligned}
$$


Comparing the coefficient of like powers of $p$, consequently, we obtain the following approximants:

$$
\begin{aligned}
p^{(0)}: y_{0}(x)= & 1 \\
p^{(1)}: y_{1}(x)= & 1+x^{2}+\left(\frac{1}{6} A-\frac{1}{6}\right) x^{3}+\left(\frac{1}{24} B+\frac{1}{24}\right) x^{4}-e^{-x} \\
p^{(2)}: y_{2}(x)= & +x^{2}+\left(\frac{1}{6} A-\frac{1}{6}\right) x^{3}+\left(\frac{1}{24} B+\frac{1}{24}\right) x^{4}-e^{-x}+70 A+140 B+\frac{2111}{16} \\
& -\left(\frac{575}{8}+40 A+70 B+(60+30 A+70 B) e^{-x}\right) x \\
& +\left(\frac{143}{8}+10 A+15 B-(12+5 A+15 B) e^{-x}\right) x^{2} \\
& -\left(\frac{31}{12}+\frac{4}{3} A+\frac{5}{3} B+\left(\frac{4}{3}+\frac{1}{3} A+\frac{5}{3} B\right) e^{-x}\right) x^{3} \\
& +\left(\frac{5}{24}+\frac{1}{12} A+\frac{1}{12} B-\left(\frac{1}{12}+\frac{1}{12} B\right) e^{-x}\right) x^{4} \\
& \times\left((132+70 A+140 B) e^{-x}\right)+\frac{1}{16} e^{-2 x} \\
&
\end{aligned}
$$

The series solution is given as

$$
\begin{aligned}
y(x)= & 1+x+\frac{1}{2} x^{2}+\frac{1}{6} A x^{3}+\frac{1}{24} B x^{4}+\frac{1}{120} x^{5}+\frac{1}{720} x^{6}+\frac{1}{5040} x^{7}+\left(\frac{1}{20160} A-\frac{1}{40320}\right) x^{8} \\
& +\left(\frac{1}{18144}-\frac{1}{362880}\right) x^{9}+\frac{1}{3628800} x^{10}+\left(\frac{1}{995840} A^{2}-\frac{1}{997920} A+\frac{1}{1900800}\right) x^{11} \\
& +\left(-\frac{1}{3421440} A^{2}+\frac{1}{2280960} A-\frac{1}{6842880} B+\frac{1}{6842880} A B-\frac{101}{479001600}\right) x^{12}+O\left(x^{13}\right) .
\end{aligned}
$$

Imposing the boundary conditions at $x=1$ and using $y(1)=y^{\prime}(1)=e$ leads to the following system:

$$
\begin{gathered}
\frac{32863}{197120} A+\frac{1996097}{47900160} B+\frac{1}{4790016} A^{2}+\frac{1}{6842880} A B=e-\frac{1202243083}{479001600}, \\
\frac{285343}{570240} A+\frac{665471}{3991680} B+\frac{1}{498960} A^{2}+\frac{1}{570240} A B=e-\frac{2729207}{1330560} .
\end{gathered}
$$

The solution of the above system gives

$$
A=0.9999967742, \quad B=1.0000145020 .
$$


Table 1: Error estimates.

\begin{tabular}{lccccccc}
\hline \multirow{2}{*}{ Exact solution } & \multicolumn{7}{c}{${ }^{*}$ Errors } \\
& & HPM & B-spline & VIM & ADM & ITM & VIMHP \\
\hline 0.0 & 1.000000000 & 0.000 & 0.0000 & 0.000 & 0.000 & 0.000 & 0.000 \\
0.1 & 1.105170918 & $1.0 \mathrm{E}-9$ & $-7.0 \mathrm{E}-4$ & $1.0 \mathrm{E}-9$ & $1.0 \mathrm{E}-9$ & $1.0 \mathrm{E}-9$ & $1.0 \mathrm{E}-9$ \\
0.2 & 1.221402758 & $2.0 \mathrm{E}-9$ & $-7.2 \mathrm{E}-4$ & $2.0 \mathrm{E}-9$ & $2.0 \mathrm{E}-9$ & $2.0 \mathrm{E}-9$ & $2.0 \mathrm{E}-9$ \\
0.3 & 1.349858808 & $1.0 \mathrm{E}-8$ & $4.1 \mathrm{E}-4$ & $1.0 \mathrm{E}-8$ & $1.0 \mathrm{E}-8$ & $1.0 \mathrm{E}-8$ & $1.0 \mathrm{E}-8$ \\
0.4 & 1.491824698 & $2.0 \mathrm{E}-8$ & $4.6 \mathrm{E}-4$ & $2.0 \mathrm{E}-8$ & $2.0 \mathrm{E}-8$ & $2.0 \mathrm{E}-8$ & $2.0 \mathrm{E}-8$ \\
0.5 & 1.648721271 & $3.1 \mathrm{E}-8$ & $4.7 \mathrm{E}-4$ & $3.1 \mathrm{E}-8$ & $3.1 \mathrm{E}-8$ & $3.1 \mathrm{E}-8$ & $3.1 \mathrm{E}-8$ \\
0.6 & 1.822118800 & $3.7 \mathrm{E}-8$ & $4.8 \mathrm{E}-4$ & $3.7 \mathrm{E}-8$ & $3.7 \mathrm{E}-8$ & $3.7 \mathrm{E}-8$ & $3.7 \mathrm{E}-8$ \\
0.7 & 2.013752707 & $4.1 \mathrm{E}-8$ & $3.9 \mathrm{E}-4$ & $4.1 \mathrm{E}-8$ & $4.1 \mathrm{E}-8$ & $4.1 \mathrm{E}-8$ & $4.1 \mathrm{E}-8$ \\
0.8 & 2.225540928 & $3.1 \mathrm{E}-8$ & $3.1 \mathrm{E}-4$ & $3.1 \mathrm{E}-8$ & $3.1 \mathrm{E}-8$ & $3.1 \mathrm{E}-8$ & $3.1 \mathrm{E}-8$ \\
0.9 & 2.459603111 & $1.4 \mathrm{E}-8$ & $1.6 \mathrm{E}-4$ & $1.4 \mathrm{E}-8$ & $1.4 \mathrm{E}-8$ & $1.4 \mathrm{E}-8$ & $1.4 \mathrm{E}-8$ \\
1.0 & 2.718281828 & 0.000 & 0.000 & 0.000 & 0.000 & 0.000 & 0.000 \\
\hline \multirow{2}{*}{ Error $=$ exact solution - series solution. }
\end{tabular}

Consequently, the series solution is given as

$$
\begin{aligned}
y(x)= & 1+x+0.5 x^{2}+0.166666236 x^{3}+0.04166727092 x^{4}+0.008333333333 x^{5}+0.00138888888 x^{6} \\
& +0.000198412 x^{7}+0.00002480142729 x^{8}+0.00005236 x^{9}+0.000000275 x^{10} \\
& -0.00000898 x^{11}-0.000000064 x^{12}+O\left(x^{13}\right)
\end{aligned}
$$

which is in full agreement with [4-7].

Table 1 shows the exact values and the errors obtained by using the homotopy perturbation method (HPM) [4], variational iteration method (VIM) [5], decomposition method (ADM) [7], the sixth degree B-spline method [1], iterative method (ITM) [6], and the variational iteration method using He's polynomials (VIMHP) for $x=0.0,0.1,0.2, \ldots, 1.0$. The table clearly indicates the improvements as compared with B-spline method. Higher accuracy can be obtained by evaluating more components of $y(x)$.

Remark 5.2. The numerical results clearly indicate that the results obtained by HPM, VIM, ADM, ITM, and the proposed VIMHP are the same. Moreover, it shows the improvements as compare to B-spline method.

Example 5.3 (see [4-7]). Consider the following linear boundary value problem of fifth-order:

$$
y^{(v)}(x)=y-15 e^{x}-10 x e^{x}
$$

with boundary conditions

$$
y(0)=0, \quad y^{\prime}(0)=1, \quad y^{\prime \prime}(0)=0 ; \quad y(1)=0, \quad y^{\prime}(1)=-e .
$$

The exact solution of the problem is

$$
y(x)=x(1-x) e^{x} .
$$


The correct functional for the boundary value problem (5.13) and (5.14) is given as

$$
y_{n+1}(x)=y_{n}(x)+\int_{0}^{x} \lambda(s)\left(\frac{d^{5} y_{n}}{d x^{5}}-\left(\tilde{y}_{n}(x)-15 e^{x}-10 x e^{x}\right)\right) d s .
$$

Making the correct functional stationary, using $\lambda=(1 / 4 !)(s-x)^{4}$, as the Lagrange multiplier $[13-18,36]$, we get the following iterative formula:

$$
\begin{aligned}
& y_{n+1}(x)=y_{n}(x)+\int_{0}^{x} \frac{1}{4 !}(s-x)^{4}\left(\frac{d^{5} y_{n}}{d x^{5}}-\left(\tilde{y}_{n}(x)-15 e^{x}-10 x e^{x}\right)\right) d s \\
& y_{n+1}(x)=x+\frac{1}{3 !} A x^{3}+\frac{1}{4 !} B x^{4}+\int_{0}^{x} \frac{1}{4 !}(s-x)^{4}\left(\frac{d^{5} y_{n}}{d x^{5}}-\left(\tilde{y}_{n}(x)-15 e^{x}-10 x e^{x}\right)\right) d s,
\end{aligned}
$$

where

$$
A=y^{\prime \prime \prime}(0), \quad B=y^{(i v)}(0) .
$$

Applying the variational iteration method using $\mathrm{He}^{\prime}$ s polynomials,

$$
\begin{aligned}
y_{0}+p y_{1}+p^{2} y_{2}+\cdots= & x+\frac{1}{3 !} A x^{3}+\frac{1}{4 !} B x^{4} \\
& +p \int_{0}^{x} \frac{1}{4 !}(s-x)^{4}\left(\frac{d^{5} y_{0}}{d x^{5}}+p \frac{d^{5} y_{1}}{d x^{5}}+p^{2} \frac{d^{5} y_{2}}{d x^{5}}+p^{3} \frac{d^{5} y_{3}}{d x^{5}}+\cdots\right) d s \\
& +p \int_{0}^{x} \frac{1}{4 !}(s-x)^{4}\left(15 e^{x}+10 x e^{x}-\left(\widetilde{y}_{0}+p \tilde{y}_{1}+p^{2} \widetilde{y}_{2}+\cdots\right)\right) d s
\end{aligned}
$$

Comparing the coefficient of like powers of $p$, consequently, we obtain the following approximants:

$$
\begin{aligned}
p^{(0)}: y_{0}(x)= & -35-24 x-\frac{15}{3} x^{2}+\left(\frac{1}{6} A-\frac{5}{6}\right) x^{3}+\left(\frac{5}{24}+\frac{1}{24} B\right) x^{4}+(35-10 x) e^{x}, \\
p^{(1)}: y_{1}(x)= & -120-99 x-40 x^{2}+\left(\frac{1}{6} A-10\right) x^{3}+\left(-\frac{40}{24}+\frac{1}{24} B\right) x^{4} \\
& -\frac{7}{24} x^{5}-\frac{1}{30} x^{6}-\frac{1}{336} x^{7}+\left(\frac{1}{40320} A-\frac{1}{8064}\right) x^{8} \\
& +\left(\frac{1}{362880} B+\frac{1}{72576}\right) x^{9}+(120-20 x) e^{x}, \\
p^{(2)}: y_{2}(x)= & -255-224 x-\frac{195}{2} x^{2}+\left(\frac{1}{6} A-\frac{55}{2}\right) x^{3}+\left(-\frac{135}{24}+\frac{1}{24} B\right) x^{4} \\
& -x^{5}-\frac{63}{1440} x^{6}-\frac{26}{1008} x^{7}+\left(\frac{1}{40320} A-\frac{12}{8064}\right) x^{8} \\
& +\left(\frac{1}{362880} B-\frac{8}{72576}\right) x^{9}-\frac{1}{103680} x^{10} \\
& -\frac{1}{166320} x^{11}-\frac{1}{31933440} x^{12}+(255-30 x) e^{x}+\cdots \\
& +\cdots
\end{aligned}
$$


Table 2: Error estimates.

\begin{tabular}{lccccccc}
\hline$x$ & Exact solution & \multicolumn{7}{c}{${ }^{*}$ Errors } \\
& & HPM & B-spline & VIM & ADM & \multicolumn{1}{c}{ ITM } & VIMHP \\
\hline 0.0 & 0.000000 & 0.0000 & 0.0000 & 0.0000 & 0.0000 & 0.0000 & 0.0000 \\
0.1 & 0.099465 & $-3 \mathrm{E}-11$ & $-8.0 \mathrm{E}-3$ & $-3 \mathrm{E}-11$ & $-3 \mathrm{E}-11$ & $-3 \mathrm{E}-11$ & $-3 \mathrm{E}-11$ \\
0.2 & 0.195424 & $-2 \mathrm{E}-10$ & $-1.2 \mathrm{E}-3$ & $-2 \mathrm{E}-10$ & $-2 \mathrm{E}-10$ & $-2 \mathrm{E}-10$ & $-2 \mathrm{E}-10$ \\
0.3 & 0.283470 & $-4 \mathrm{E}-10$ & $-5.0 \mathrm{E}-3$ & $-4 \mathrm{E}-10$ & $-4 \mathrm{E}-10$ & $-4 \mathrm{E}-10$ & $-4 \mathrm{E}-10$ \\
0.4 & 0.358038 & $-8 \mathrm{E}-10$ & $3.0 \mathrm{E}-3$ & $-8 \mathrm{E}-10$ & $-8 \mathrm{E}-10$ & $-8 \mathrm{E}-10$ & $-8 \mathrm{E}-10$ \\
0.5 & 0.412180 & $-1.2 \mathrm{E}-9$ & $8.0 \mathrm{E}-3$ & $-1.2 \mathrm{E}-9$ & $-1.2 \mathrm{E}-9$ & $-1.2 \mathrm{E}-9$ & $-1.2 \mathrm{E}-9$ \\
0.6 & 0.437309 & $-2 \mathrm{E}-9$ & $6.0 \mathrm{E}-3$ & $-2 \mathrm{E}-9$ & $-2 \mathrm{E}-9$ & $-2 \mathrm{E}-9$ & $-2 \mathrm{E}-9$ \\
0.7 & 0.422888 & $-2.2 \mathrm{E}-9$ & -0.000 & $-2.2 \mathrm{E}-9$ & $-2.2 \mathrm{E}-9$ & $-2.2 \mathrm{E}-9$ & $-2.2 \mathrm{E}-9$ \\
0.8 & 0.356087 & $-1.9 \mathrm{E}-9$ & $9.0 \mathrm{E}-3$ & $-1.9 \mathrm{E}-9$ & $-1.9 \mathrm{E}-9$ & $-1.9 \mathrm{E}-9$ & $-1.9 \mathrm{E}-9$ \\
0.9 & 0.221364 & $-1.4 \mathrm{E}-9$ & $-9.0 \mathrm{E}-3$ & $-1.4 \mathrm{E}-9$ & $-1.4 \mathrm{E}-9$ & $-1.4 \mathrm{E}-9$ & $-1.4 \mathrm{E}-9$ \\
1.0 & 0.000000 & 0.000 & 0.000000 & 0.000 & 0.000 & 0.000 & 0.000 \\
\hline
\end{tabular}

The series solution is given as

$$
\begin{aligned}
y(x)= & x+\frac{1}{6} A x^{3}+\frac{1}{24} B x^{4}-\frac{1}{8} x^{5}-\frac{1}{30} x^{6}-\frac{1}{144} x^{7}+\left(-\frac{1}{896}+\frac{1}{40320} A\right) x^{8} \\
& +\left(-\frac{1}{72576}+\frac{1}{362880} B\right) x^{9}-\frac{1}{45360} x^{10}+\frac{1}{403200} x^{11}-\frac{1}{3991680} x^{12}-\frac{A}{622702080} x^{12} \\
& -\frac{1}{44478720} x^{13}-\left(\frac{B}{8717029120}-\frac{1}{544864320}\right) x^{14}+O\left(x^{15}\right) .
\end{aligned}
$$

Imposing the boundary conditions at $x=1$ and using $y(1)=y^{\prime}(1)=-e$ leads to the following system:

$$
\begin{aligned}
& \frac{148284463}{889574400} A+\frac{15121}{362880} B=-\frac{648723077}{778377600} \\
& \frac{239595841}{479001600} A+\frac{6721}{40320} B=-e-\frac{3468127}{29937600} .
\end{aligned}
$$

The solution of the above system gives

$$
A=-2.99999988, \quad B=-8.00000054 .
$$

The series solution is given by

$$
\begin{aligned}
y(x)= & x-0.49999998 x^{3}-0.33333355 x^{4}-0.125 x^{5}-0.03333333 x^{6}-0.006944444 x^{7} \\
& -0.0011904762 x^{8}-0.0001736111 x^{9}-0.0000220458 x^{10}-0.000002488 x^{11} \\
& -0.000000244 x^{12}-0.000000022 x^{13}-0.000000001 x^{14}+O\left(x^{15}\right)
\end{aligned}
$$

which is in full agreement with [4-7].

Table 2 shows the exact values and the errors obtained by using the homotopy perturbation method (HPM) [4], variational iteration method (VIM) [5], decomposition method (ADM) 
[7], the sixth degree B-spline method [1], iterative method (ITM) [6], and the variational iteration method using He's polynomials (VIMHP) for $x=0.0,0.1,0.2, \ldots, 1.0$. The table clearly indicates the improvements as compared with B-spline method. Higher accuracy can be obtained by evaluating more components of $y(x)$.

Remark 5.4. The numerical results clearly indicate that the results obtained by HPM, VIM, ADM, ITM, and the proposed VIMHP are the same. Moreover, it shows the improvements as compare to B-spline method.

\section{Conclusions}

In this paper, we applied the variational iteration method using He's polynomials (VIMHP) for finding the solution of boundary value problems of fifth-order. The method is applied in a direct way without using linearization, transformation, discretization, or restrictive assumptions. It may be concluded that VIMHP is very powerful and efficient in finding the analytical solutions for a wide class of boundary value problems. The method gives more realistic series solutions that converge very rapidly in physical problems. It is worth mentioning that the method is capable of reducing the volume of the computational work as compared to the classical methods while still maintaining the high accuracy of the numerical result, the size reduction amounts to the improvement of performance of approach. The fact that the VIMHP solves nonlinear problems without using Adomian's polynomials is a clear advantage of this technique over the decomposition method.

\section{Acknowledgments}

The authors are highly grateful to both the Referees and Professor David Chelidze for their constructive comments. They would like to thank Dr. S. M. Junaid Zaidi, Rector CIIT, for providing excellent research environment and facilities.

\section{References}

[1] H. N. Çaglar, S. H. Çaglar, and E. H. Twizell, "The numerical solution of fifth-order boundary value problems with sixth-degree B-spline functions," Applied Mathematics Letters, vol. 12, no. 5, pp. 25-30, 1999.

[2] A. R. Davies, A. Karageorghis, and T. N. Phillips, "Spectral Galerkin methods for the primary twopoint boundary value problem in modelling viscoelastic flows," International Journal for Numerical Methods in Engineering, vol. 26, no. 3, pp. 647-662, 1988.

[3] D. J. Fyfe, "Linear dependence relations connecting equal interval $N$ th degree splines and their derivatives," Journal of the Institute of Mathematics and Its Applications, vol. 7, no. 3, pp. 398-406, 1971.

[4] M. A. Noor and S. T. Mohyud-Din, "An efficient algorithm for solving fifth-order boundary value problems," Mathematical and Computer Modelling, vol. 45, no. 7-8, pp. 954-964, 2007.

[5] M. A. Noor and S. T. Mohyud-Din, "Variational iteration technique for solving higher order boundary value problems," Applied Mathematics and Computation, vol. 189, no. 2, pp. 1929-1942, 2007.

[6] M. A. Noor and S. T. Mohyud-Din, "Modified decomposition method for solving linear and nonlinear fifth-order boundary value problems," International Journal of Applied Mathematics and Computer Science. In press.

[7] A.-M. Wazwaz, "The numerical solution of fifth-order boundary value problems by the decomposition method," Journal of Computational and Applied Mathematics, vol. 136, no. 1-2, pp. 259-270, 2001. 
[8] J.-H. He, "Homotopy perturbation method for solving boundary value problems," Physics Letters A, vol. 350, no. 1-2, pp. 87-88, 2006.

[9] J.-H. He, "Comparison of homotopy perturbation method and homotopy analysis method," Applied Mathematics and Computation, vol. 156, no. 2, pp. 527-539, 2004.

[10] J.-H. He, "Homotopy perturbation method for bifurcation of nonlinear problems," International Journal of Nonlinear Sciences and Numerical Simulation, vol. 6, no. 2, pp. 207-208, 2005.

[11] J.-H. He, "The homotopy perturbation method for nonlinear oscillators with discontinuities," Applied Mathematics and Computation, vol. 151, no. 1, pp. 287-292, 2004.

[12] J.-H. He, "A coupling method of a homotopy technique and a perturbation technique for nonlinear problems," International Journal of Non-Linear Mechanics, vol. 35, no. 1, pp. 37-43, 2000.

[13] J.-H. He, "Variational iteration method-some recent results and new interpretations," Journal of Computational and Applied Mathematics, vol. 207, no. 1, pp. 3-17, 2007.

[14] J.-H. He, "Variational iteration method—a kind of nonlinear analytical technique: some examples," International Journal of Non-Linear Mechanics, vol. 34, no. 4, pp. 699-708, 1999.

[15] J.-H. He, "Variational iteration method for autonomous ordinary differential systems," Applied Mathematics and Computation, vol. 114, no. 2-3, pp. 115-123, 2000.

[16] J. H. He and X. H. Wu, "Construction of solitary solution and compacton-like solution by variational iteration method," Chaos, Solitons \& Fractals, vol. 29, no. 1, pp. 108-113, 2006.

[17] J.-H. He, "Some asymptotic methods for strongly nonlinear equations," International Journal of Modern Physics B, vol. 20, no. 10, pp. 1141-1199, 2006.

[18] J.-H. He, "The variational iteration method for eighth-order initial-boundary value problems," Physica Scripta, vol. 76, no. 6, pp. 680-682, 2007.

[19] M. Inokuti, H. Sekine, and T. Mura, "General use of the Lagrange multiplier in nonlinear mathematical physics," in Variational Method in the Mechanics of Solids, S. Nemat-Naseer, Ed., pp. 156-162, Pergamon Press, New York, NY, USA, 1978.

[20] S. Abbasbandy, "Numerical solution of nonlinear Klein-Gordon equations by variational iteration method," International Journal for Numerical Methods in Engineering, vol. 70, no. 7, pp. 876-881, 2007.

[21] S. Abbasbandy, "A new application of He's variational iteration method for quadratic Riccati differential equation by using Adomian's polynomials," Journal of Computational and Applied Mathematics, vol. 207, no. 1, pp. 59-63, 2007.

[22] S. Abbasbandy, "Numerical method for nonlinear wave and diffusion equations by the variational iteration method," International Journal for Numerical Methods in Engineering, vol. 73, no. 12, pp. 18361843, 2008.

[23] A. Ghorbani and J. Saberi-Nadjafi, "He's homotopy perturbation method for calculating adomian polynomials," International Journal of Nonlinear Sciences and Numerical Simulation, vol. 8, no. 2, pp. 229232, 2007.

[24] A. Ghorbani, "Beyond Adomian's polynomials: He polynomials," Chaos, Solitons E Fractals. In press.

[25] S. Momani and S. Abuasad, "Application of He's variational iteration method to Helmholtz equation," Chaos, Solitons \& Fractals, vol. 27, no. 5, pp. 1119-1123, 2006.

[26] S. T. Mohyud-Din, "A reliable algorithm for Blasius equation," in Proceedings of the International Conference of Mathematical Sciences (ICMS '07), pp. 616-626, Bangi-Putrajaya, Malaysia, November 2007.

[27] S. T. Mohyud-Din and M. A. Noor, "Homotopy perturbation method for solving fourth-order boundary value problems," Mathematical Problems in Engineering, vol. 2007, Article ID 98602, 15 pages, 2007.

[28] M. A. Noor and S. T. Mohyud-Din, "Homotopy perturbation method for solving sixth-order boundary value problems," Computers and Mathematics with Applications. In press.

[29] M. A. Noor and S. T. Mohyud-Din, "Homotopy method for solving eighth order boundary value problems," Journal of Mathematical Analysis and Approximation Theory, vol. 1, no. 2, pp. 161-169, 2006.

[30] M. A. Noor and S. T. Mohyud-Din, "Approximate solutions of Flieral Petviashivili equation and its variants," International Journal of Mathematics and Computer Science, vol. 2, no. 4, pp. 345-360, 2007.

[31] M. A. Noor and S. T. Mohyud-Din, "A reliable approach for solving linear and nonlinear sixth-order boundary value problems," International Journal of Computational and Applied Mathematics. In press.

[32] M. A. Noor and S. T. Mohyud-Din, "An efficient method for fourth-order boundary value problems," Computers and Mathematics with Applications, vol. 54, no. 7-8, pp. 1101-1111, 2007. 
[33] M. A. Noor and S. T. Mohyud-Din, "Variational iteration technique for solving tenth-order boundary value problems," Applied Mathematics and Computation, vol. 189, no. 2, pp. 1929-1942, 2007.

[34] M. A. Noor and S. T. Mohyud-Din, "Variational iteration decomposition method for solving eighthorder boundary value problems," Differential Equations and Nonlinear Mechanics. In press.

[35] J. I. Ramos, "On the variational iteration method and other iterative techniques for nonlinear differential equations," Applied Mathematics and Computation. In press.

[36] L. Xu, "The variational iteration method for fourth-order boundary value problems," Chaos, Solitons $\mathcal{E}$ Fractals. In press. 


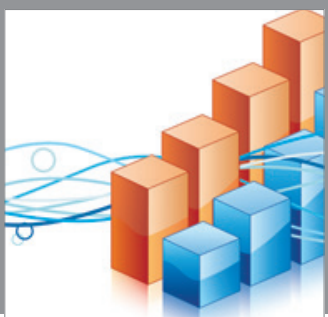

Advances in

Operations Research

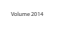

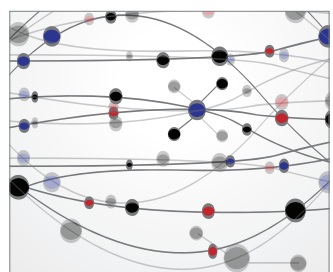

\section{The Scientific} World Journal
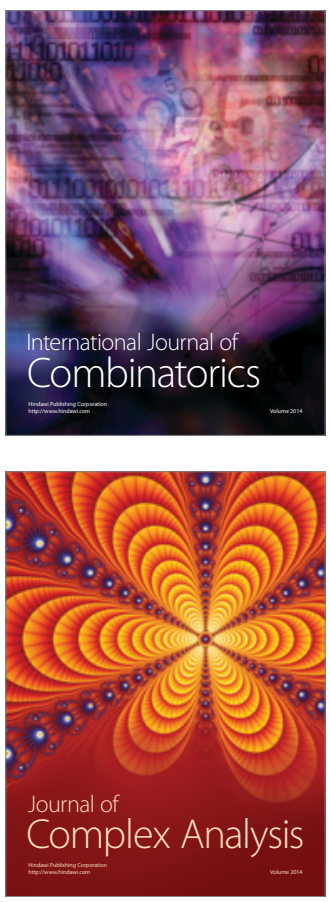

International Journal of

Mathematics and

Mathematical

Sciences
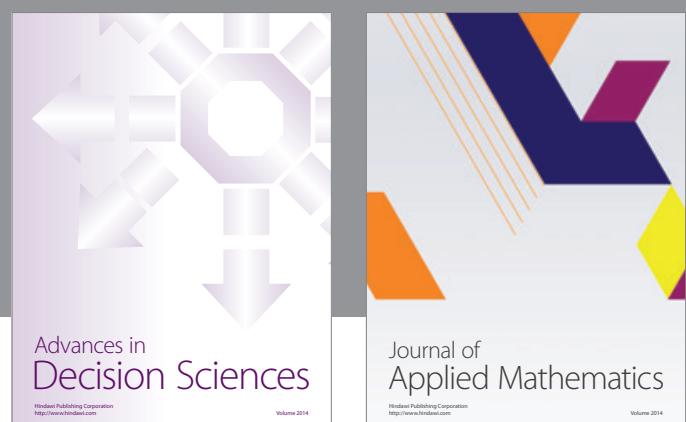

Journal of

Applied Mathematics
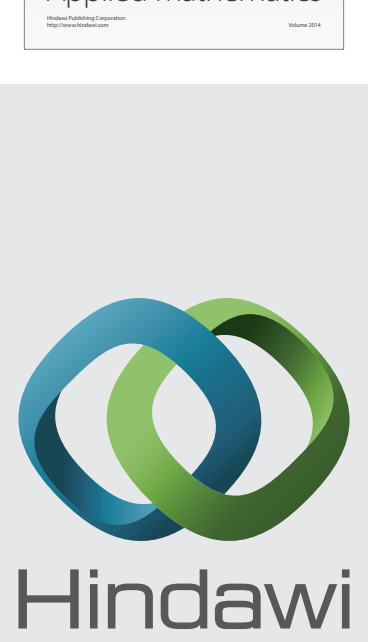

Submit your manuscripts at http://www.hindawi.com
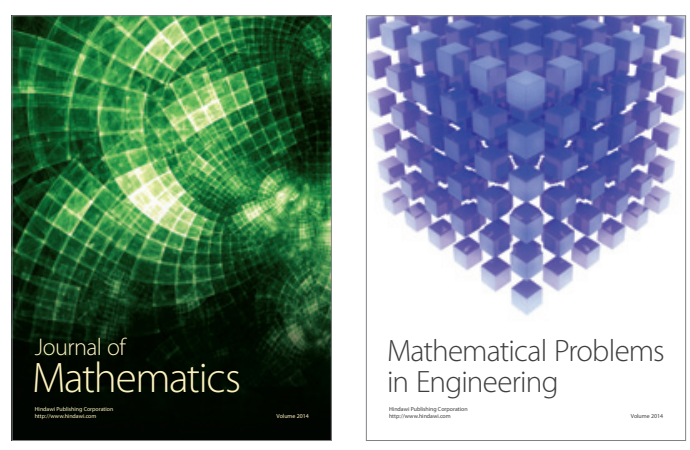

Mathematical Problems in Engineering
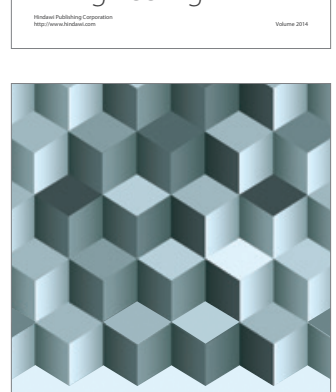

Journal of

Function Spaces
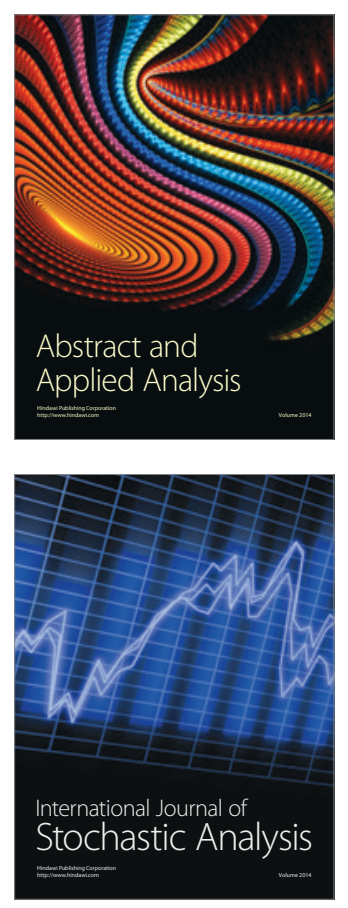

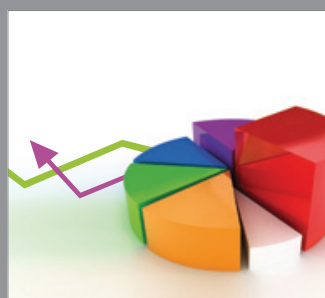

ournal of

Probability and Statistics

Promensencen
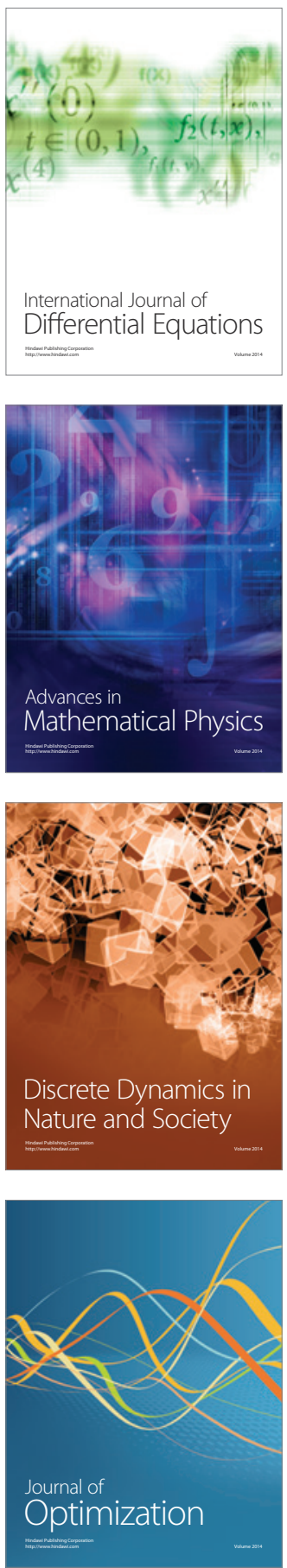